\title{
药 \\ AUXÍLIO EMERGENCIAL NA PANDEMIA DA COVID-19: ATUAÇÃO DO LEGISLATIVO PARA A REDUÇÃO DE VULNERABILIDADES
}

\author{
EMERGENCY AID DURING THE COVID-19 PANDEMIC: LEGISLATIVE \\ ACTION TO REDUCE VULNERABILITIES
}

\author{
AYUDA EMERGENCIAL EN LA PANDEMIA DEL COVID-19: ACCIÓN \\ LEGISLATIVA PARA REDUCIR VULNERABILIDADES
}

\author{
Ana Luíza Matos De Oliveira ${ }^{1}$
}

\begin{abstract}
Resumo: A pandemia da Covid-19 gerou uma crise sem precedentes, alcançando o Brasil em um momento de fragilidade do Estado brasileiro, com baixo crescimento econômico, precarização no mercado de trabalho e uma redução crônica do financiamento para políticas públicas no Brasil. No primeiro semestre de 2020, o Congresso Nacional teve papel primordial no enfrentamento à pandemia, em especial com a criação do auxílio emergencial, sobre a qual há um processo de disputa da narrativa. Neste sentido, este artigo retoma a situação de vulnerabilidade dos trabalhadores brasileiros às vésperas da pandemia, discute a ampliação das vulnerabilidades durante a crise e apresenta o processo de criação do auxílio emergencial. O Congresso Nacional deve decidir se, ao invés de o auxílio emergencial ser integrado a uma provisão pública de direitos sociais, ele será usado para reduzir ainda mais o papel do Estado.
\end{abstract}

Palavras-chave: Covid-19; Auxílio emergencial; Legislativo; Congresso Nacional; Brasil.

Abstract: The Covid-19 pandemic generated an unprecedented crisis, reaching Brazil at a time of fragility for the Brazilian State, with low economic growth, precarious employment conditions and a chronic reduction in funding for public policies in Brazil. In the first half of 2020, the National Congress played a major role in tackling the pandemic, especially with the creation of emergency aid, over which there is a dispute over its narrative. In this sense, this article summarizes the situation of vulnerability of Brazilian workers on the eve of the pandemic, discusses the expansion of vulnerabilities during the crisis and presents the process of creating emergency aid. The National Congress must decide whether, instead of the emergency aid being integrated into a public provision of social rights, it will be used to further reduce the role of the state.

Keywords: Covid-19; Emergency benefit; Legislative; National Congress; Brazil.

Resumen: La pandemia del Covid-19 generó una crisis sin precedentes, llegando a Brasil en un momento de fragilidad para el Estado brasileño, con bajo crecimiento económico, condiciones de empleo precarias y una reducción crónica del financiamiento de las políticas públicas en Brasil. En el primer semestre de 2020, el Congreso Nacional tuvo un papel importante en el enfrentamiento de la pandemia, especialmente con la creación de la ayuda emergencial, sobre la cuál existe una disputa de narrativa. En este sentido, este artículo retoma la situación de vulnerabilidad de los trabajadores brasileños en vísperas de la pandemia, analiza la expansión de vulnerabilidades durante la crisis y presenta el proceso de creación de ayuda de emergencia. El Congreso Nacional debe decidir si, en lugar de que la ayuda emergencial se integre en una disposición pública de derechos sociales, será utilizada para reducir aún más el papel del estado.

Palabras clave: Covid-19; Ayuda emergencial; Legislativo; Congreso Nacional; Brasil.

\footnotetext{
${ }^{1}$ É professora visitante da FLACSO Brasil e Coordenadora-Geral da Secretaria Executiva da Frente Parlamentar Mista em Defesa do Serviço Público (Frente Servir Brasil). Além de consultora e pesquisadora, é co-editora do WEA Commentaries e integra o membership committee da IAFFE (2020-2021). É economista (UFMG), doutora em Desenvolvimento Econômico (Unicamp).
} 


\section{Introdução}

A pandemia da Covid-19 trouxe uma crise sem precedentes a um país que vivia anos de baixo crescimento econômico, precarização no mercado de trabalho e redução crônica do financiamento para políticas públicas no Brasil (OLIVEIRA et. al, 2020). Neste sentido, o Estado brasileiro tem tido dificuldades de responder de forma rápida e contundente à crise.

Há de se destacar, no entanto, o papel de liderança do legislativo federal no enfrentamento à pandemia no primeiro semestre de 2020. Segundo levantamento do Congresso Nacional, a casa foi autora de $92 \%$ das medidas contra a crise da Covid-19 que foram transformadas em lei até meados do ano de 2020 (ISTO É, 2020). Uma das importantes iniciativas para a redução dos impactos da crise da Covid-19 que partiu do Congresso Nacional foi o auxílio emergencial. Apesar de a medida aprovada ter partido do Congresso Nacional, há um processo de disputa da narrativa quanto à criação do programa. Por isso, o objetivo deste artigo é enfocar a atuação do legislativo para a aprovação do auxílio como resolução de vulnerabilidades até mesmo prévias à pandemia, e mesmo enquanto o Governo Federal relutava em adotar um programa da magnitude do que acabou por ser implementado.

Neste sentido, o artigo retoma a situação de vulnerabilidade dos trabalhadores brasileiros às vésperas da pandemia, discute a ampliação das vulnerabilidades durante a crise e por fim apresenta como o auxílio emergencial foi criado. O artigo é finalizado com considerações finais.

\section{Vulnerabilidades sociais no Brasil às vésperas da pandemia: um histórico}

O Brasil é um país que se destaca por suas desigualdades de renda, de gênero e raciais, com profundas raízes históricas. O mercado de trabalho brasileiro historicamente apresenta características de um país de capitalismo tardio, com heterogeneidade estrutural que se reforçaram nos anos 1990 (FORNAZIER; OLIVEIRA, 2013). Porém, no início do século XXI, houve uma melhoria de diversos indicadores do mercado de trabalho brasileiro, tais como o crescimento do emprego, especialmente o formalizado, a redução proporcional dos ocupados sem proteção previdenciária, melhora na renda do trabalho e uma diminuição da desigualdade da renda do trabalho. A política de aumento do salário mínimo com expansão da proteção social, transferências de renda, melhorias nas condições de negociações coletivas e o acesso ao crédito contribuíram para melhorias no mercado de trabalho (DIEESE, 2017).

A partir de 2015, o mercado de trabalho sofre o impacto da crise econômica e da adoção da austeridade fiscal (OLIVEIRA et al., 2020). A taxa de desocupação cresceu e só passa a cair a partir de 2017, ainda que se mantivesse em níveis muito altos. Porém, esta queda foi acompanhada do aumento da subutilização (e desalento) e da informalidade, mesmo com a Reforma Trabalhista em 2017, aprovada com a justificativa de que iria aumentar o emprego formal. Indicadores 
apontam o crescimento do "empreendedorismo" e do número de trabalhadores conta própria, por exemplo com a expansão da chamada "uberização do trabalho" (ABÍLIO, 2017), com renda variável e alta vulnerabilidade. Simultânea a essa piora no mercado de trabalho, Oxfam (2018) defendia que "a rota da redução das desigualdades parou no Brasil" (OXFAN, 2018, p.11) e que indicadores negativos mostravam "grave recuo do progresso social" (OXFAN, 2018, p. 11). Também a pobreza e a miséria, que tinham caído drasticamente até meados da segunda década do século XXI, cresceram nos anos recentes no Brasil e se relacionam ao aumento do trabalho infantil e juvenil (FUNDAÇÃO ABRINQ, 2017; IBGE, 2018; OLIVEIRA, 2019).

É a partir desde quadro de ampliação da vulnerabilidade social nos anos recentes que a pandemia de Covid-19 atinge o Brasil. Às vésperas da pandemia, no $1^{\circ}$ trimestre de 2020, o Brasil contava 36,8 milhões de trabalhadores informais, o equivalente a 39,9\% da população ocupada do país, além de 12,9 milhões de desocupados e 67,3 milhões de pessoas fora da força de trabalho, um recorde da série histórica iniciada em 2012 (IBGE, 2020). Também às vésperas da pandemia, em janeiro de 2020, 700 mil famílias aguardavam na fila de entrada ao Programa Bolsa Família (PBF), enquanto a cobertura do Programa caía (em janeiro de 2019, 13,8 milhões de famílias eram beneficiárias, chegando a 14,3 em maio e caindo a 13,1 em dezembro). Também, em troca do "13 salário", em 2020 não houve correção inflacionária do benefício em 2019 (OLIVEIRA et al., 2020).

\section{Tateando os efeitos da pandemia de Covid-19 nos mais vulneráveis}

As estimativas de impacto social e econômico da pandemia na América Latina e no Brasil são profundas (OLIVEIRA; EMÍDIO, 2020). Recentemente, a Cepal estimou a queda do PIB da América Latina e Caribe em 5,3\% em 2020 (e para o Brasil de 5,2\%) (CEPAL, 2020a). Já o FMI estima queda do PIB de 5,3\% para o Brasil (FMI, 2020). Seguindo essa previsão, desde 2015 o PIB do Brasil estaria em uma trajetória em "W", com queda brusca até 2016, uma "recuperação" em termos até 2019 (que, porém, não recompõe nem o patamar inicial), com nova queda brusca em 2020, completando a pior a crise econômica da história do país em termos de queda do PIB (MELLO et al., 2020).

No Brasil, a pandemia amplia o fosso das desigualdades, sejam elas raciais, de gênero ou de renda (NASSIF-PIRES et al., 2020, ALLOATTI; OLIVEIRA, 2020). As mortes por Covid-19 no Brasil estão se concentrando em regiões mais pobres das grandes cidades. Nas periferias, a situação de pobreza e vulnerabilidade no mercado de trabalho, com muitos trabalhadores no mercado informal, se relaciona à precariedade das moradias e do saneamento básico, que impedem a realização do isolamento social e dos hábitos de higiene de forma adequada para se proteger do vírus (OLIVEIRA; EMÍDIO, 2020). Inclusive, o "rejuvenescimento" do perfil dos óbitos por Covid-19 no Brasil tem muito a ver com vulnerabilidade social, com informalidade, 
com a dificuldade de realizar isolamento social pela necessidade de garantir renda ou por condições precárias de moradia e de saneamento básico (PIRES, 2020).

As desigualdades de gênero ficam evidentes durante a pandemia, não só pelo aumento de casos de violência doméstica pelo contexto de crise econômica e isolamento social, como também pela ampliação do trabalho doméstico e pelo impacto no mercado de trabalho. No Brasil, as estruturas públicas que auxiliam na reprodução social, tais como creches, escolas e instituições de longa permanência, são limitados, levando a que as mulheres, devido à chamada divisão sexual do trabalho, fiquem mais sobrecarregadas (OLIVEIRA et al., 2020). No contexto da pandemia, com a ampliação do trabalho doméstico e o fechamento de muitas das já precárias estruturas que auxiliam na reprodução social, o fardo do trabalho doméstico pode estar recaindo ainda mais sobre as mulheres. Esta sobrecarga, em especial neste período, pode ter impactos de longo prazo na trajetória destas mulheres (OLIVEIRA; EMÍDIO, 2020).

Como resultado da crise, estima-se o aumento da pobreza na América Latina. Segundo Cepal e Organização Internacional do Trabalho - OIT (2020), a pobreza extrema deve subir para algo entre $13 \%$ e $14,2 \%$ em 2020 e a pobreza para algo entre $33,7 \%$ e 35,8\% em 2020 na região. Também, espera-se um aumento da desigualdade na América Latina, em especial no Brasil: a desigualdade de renda (medida pelo Índice de Gini) deve crescer 3\% ou mais no Brasil segundo a Cepal (2020b). Também é previsto que a perda de renda e emprego, além do fechamento das escolas, leve a uma ampliação do trabalho infantil (OIT, 2020; UNICEF, 2020). Particularmente em risco, segundo as instituições, estão as meninas. Por fim, alerta-se para a ampliação do desemprego entre jovens, um grupo já estruturalmente em risco, com maior vulnerabilidade e maior desocupação, com efeitos de longo prazo da crise para a "geração lockdown", marcada pela interrupção dos estudos, bem como pelo desemprego e pela perda de renda.

Para os trabalhadores informais, categoria com interfaces importantes com a pobreza e a vulnerabilidade de crianças e jovens como abordado anteriormente, o impacto da pandemia é bastante direto. Como vimos na seção anterior, esta categoria englobava no Brasil em torno de 37 milhões de trabalhadores às vésperas da crise, sem contar os 67 milhões fora do mercado de trabalho. Os informais foram altamente impactados pela crise, que em um primeiro momento se fez sentir por uma piora do cenário internacional (com as crises na China e na Europa, devido à pandemia) e posteriormente pela chegada do vírus no Brasil. Aqui, os trabalhadores informais foram altamente impactados pela brusca interrupção da atividade econômica e pelas mudanças de gasto e de hábitos das famílias (HECKSHER, 2020). Enquanto trabalhadores do setor formal tem algum tipo de auxílio caso percam seu emprego com o sistema de proteção social, os trabalhadores informais não dispõem da mesma rede de proteção. Da mesma forma os beneficiários do PBF com cobertura em queda nos últimos meses - se viram impactados pela crise no mercado de trabalho. De qualquer forma, tem sido notória a passagem de trabalhadores da ocupação para a inatividade, em especial mulheres (FERNANDES, 2020). 
Assim, um dos traços mais definidores da nossa região - a desigualdade - deve piorar com a pandemia: neste momento de forte crise, saem adiante aqueles que podem contar com reservas, apoios, redes de contato. Os que já se encontravam em maior vulnerabilidade, ficam para trás. Domingues et al. (2020) apontam que com a crise em decorrência da pandemia, as famílias mais pobres são as que mais perdem renda: as famílias mais pobres (com renda de 0 a 1 salário mínimo), terão perda de renda $20 \%$ maior que a média das famílias brasileiras.

Com a pandemia, o governo prometeu ampliar a cobertura do PBF. Porém, em maio de 2020 o programa alcançava 14,2 milhões de famílias beneficiadas: o gasto extra realizado pelo governo não foi capaz nem de zerar a fila do programa (RESENDE, 2020). Ou seja, nem os instrumentos já usuais para ampliar a rede de proteção social em períodos de grave crise social o governo tem conseguido acionar na medida necessária. Com a ampliação do desemprego, o número de famílias na fila do programa deve aumentar.

Para mitigar o impacto econômico da crise para milhões de trabalhadores vulneráveis, bem como fornecer algum tipo de alívio econômico para que estes pudessem se recolher e realizar o isolamento social, iniciou-se a pressão para a adoção de algum tipo de benefício emergencial. Mello et al. (2020), escrevendo em março de 2020, sugeria que este benefício fosse no valor de 1 salário mínimo e se estendesse para todos aqueles no Cadastro Único, trabalhadores informais não cadastrados, beneficiários do Benefício de Prestação Continuada (BPC) e Microempreendedores Individuais. À época, documentam Mello et al. (2020), a proposta de auxílio emergencial por parte do Ministério da Economia era de fornecer um voucher de R $\$ 200$ para famílias do Cadastro Único que não recebessem outros benefícios ao longo de 3 meses.

Passemos então à análise da atuação do legislativo em pressionar o governo federal para a adoção de um auxílio emergencial para as camadas mais carentes da população.

\section{A atuação do Legislativo para garantir renda em meio à pandemia: o caso do auxílio emergencial}

Em 18 de março de 2020, o ministro da economia Paulo Guedes, anunciou que o governo liberaria $\mathrm{R} \$ 15$ bilhões em benefícios de até $\mathrm{R} \$ 200$ para trabalhadores informais e autônomos por três meses, sendo R $\$ 5$ bilhões por mês para cobrir este valor para 38 milhões de informais (UOL, 2020). O benefício seria batizado de auxílio emergencial.

No entanto, o Congresso Nacional se articulou de forma a transformar o Projeto de Lei (PL) 9236/2017 de autoria do Deputado Eduardo Barbosa (PSDB-MG) em um benefício mais amplo. Em 25 de março de 2020, a matéria passou a tramitar em caráter de urgência (BRASIL, 2020). A partir da atuação do relator, Deputado Marcelo Aro (PP-MG), foi feito um substitutivo que sugeria um valor de $R \$ 500$ mensais, contra os $R \$ 200$ propostos pelo governo. O substitutivo ganhou amplo apoio no Congresso Nacional. 
O presidente da Câmara, Deputado Rodrigo Maia (DEM-RJ), afirmou que o Congresso não aceitaria menos de $\mathrm{R} \$ 500$, em oposição ao valor de $\mathrm{R} \$ 200$, pleiteado pelo governo (AGÊNCIA CÂMARA DE NOTÍCIAS, 2020). Quando se formou uma maioria nítida em favor do valor de $\mathrm{R} \$ 500$, o Palácio do Planalto cedeu e elevou o valor, passando a apresentar o benefício como sua criação, para que o auxílio não fosse visto como uma vitória do Congresso Nacional. Assim, após negociações com o líder do governo, deputado Vitor Hugo (PSL-GO), o Executivo aceitou aumentar o valor para $\mathrm{R} \$ 600$.

Por fim, o PL foi aprovado na Câmara em 26/03/2020, seguiu ao Senado, onde foi também aprovado em 30/03/2020, e ficou aguardando sanção presidencial. Foi, por fim, sancionado pelo Presidente da República na forma de lei nº 13.982/2020, de 2 de abril de 2020 (BRASIL, 2020a).

Em 02/04/2020, a estimativa oficial era de que o auxílio emergencial atendesse 54 milhões de pessoas - pouco mais de $25 \%$ da população brasileira. Neste dia, quando a lei que regulamentava o auxílio emergencial foi sancionada, o mesmo tempo, o Executivo publicou uma a Medida Provisória 937/2020 (BRASIL 2020b) para financiar o programa, em que se previa a liberação de R \$ 98,2 bilhões em créditos extraordinários para o Ministério da Cidadania para o pagamento do benefício (AGÊNCIA SENADO, 2020).

Definiu-se que um beneficiário deveria cumprir, ao mesmo tempo, os seguintes requisitos: i) ser maior de 18 anos de idade; ii) não ter emprego formal (ou seja, excluem-se todos os trabalhadores formalizados pela Consolidação das Leis do Trabalho e todos os agentes públicos, inclusive os ocupantes de cargo ou função temporários, de cargo em comissão de livre nomeação e exoneração ou titulares de mandato eletivo); iii) não receber benefício previdenciário ou assistencial, seguro-desemprego ou de outro programa de transferência de renda federal que não seja o Bolsa Família; iv) ter renda familiar mensal per capita (por pessoa) de até meio salário mínimo ( $\mathrm{R} \$ 522,50)$ ou renda familiar mensal total (tudo o que a família recebe) de até três salários mínimos ( $\mathrm{R} \$ 3.135,00)$ (considerados todos os rendimentos obtidos por todos os membros que moram na mesma residência, exceto o valor do Bolsa Família; A renda média será verificada por meio do CadÚnico para os inscritos e, para os não inscritos, com autodeclaração em plataforma digital); e v) não ter recebido rendimentos tributáveis, no ano de 2018, acima de $\mathrm{R} \$ 28.559,70$. O candidato deveria ainda cumprir uma dessas condições: i) exercer atividade na condição de microempreendedor individual (MEI); ii) ser contribuinte individual ou facultativo do Regime Geral de Previdência Social (RGPS); iii) ser trabalhador informal inscrito no Cadastro Único para Programas Sociais do Governo Federal (CadÚnico); ou iv) se for trabalhador informal sem pertencer a nenhum cadastro, é preciso ter cumprido, no último mês, o requisito de renda citado anteriormente (AGÊNCIA CÂMARA DE NOTÍCIAS, 2020). 
No entanto, quando o benefício foi finalmente começou a ser pago, multidões se aglomeraram na porta de bancos, quando a proposta do programa era justamente contribuir para o isolamento social em um contexto de pandemia $(\mathrm{G1}, 2020)$.

Passado o período de disputas para a criação do programa, ampliou-se a disputa de "narrativa" em torno de sua criação, com campanhas divulgadas por parte do Executivo para se apresentar como responsável pelo benefício (BOLSONARO, 2020), com resposta por parte do relator da matéria na Câmara dos Deputados (ARO, 2020). O Executivo também fez campanhas para divulgar que o auxílio não era iniciativa de prefeitos e governadores (SECOMVC, 2020).

A prorrogação e a ampliação do benefício são motivos de discordância entre Executivo e Legislativo em Brasília, bem como entre o próprio executivo, com supostos embates entre ministros, sendo Paulo Guedes relutante em ampliar sua validade por preocupações fiscalistas de um lado e Jair Bolsonaro receoso de perda de apoio popular com o fim do benefício. No fim de abril, o Congresso Nacional chegou a aprovar um projeto de lei que ampliava o acesso ao auxílio, mas o projeto de lei sofreu diversos vetos por parte do governo ao se transformar em Lei $13.998 / 2020$.

Com o fim das três parcelas iniciais e a pressão por sua prorrogação, foi publicado o Decreto $\mathrm{n}^{\circ} 10.412$, de 30/06/2020 (BRASIL, 2020d), para prorrogar o período de pagamento do auxílio emergencial por mais dois meses, sem alteração nos valores do benefício. Posteriormente, houve nova prorrogação, efetivada pela Medida Provisória 1.000/2020 de 02/09/2020 (BRASIL, 2020e), que o prorrogou até dezembro de 2020, ou seja, mais quatro parcelas, porém com redução de $50 \%$ do valor da parcela, passando para o montante no valor de $\mathrm{R} \$ 300,00$. Além do valor menor, a Medida Provisória também indicou novos critérios para determinar quem poderá receber as quatro parcelas residuais de $\mathrm{R} \$ 300,00$ entre setembro e dezembro de 2020 , relativos à declaração de imposto de renda de 2019 e à posse ou propriedade de bens ou direitos, incluindo terra nua, de valor acima de $\mathrm{R} \$ 300$ mil.

Partidos de oposição como o Partido dos Trabalhadores (PT), Partido Comunista do Brasil (PCdoB) e o Partido Socialismo e Liberdade (PSOL) se opuseram a cortes no valor do benefício, bem como centrais sindicais, e tem pressionado, inclusive, por novas prorrogações do benefício, alegando que a situação da população brasileira ainda é extremamente grave e que as supostas preocupações fiscalistas do Governo Federal não se sustentam em um contexto de desalento, desemprego e aumento da fome (PT, 2020; PCdoB, 2020; PSOL, 2020).

Em 18/11/2020, o balanço da Caixa Econômica Federal (2020) mostrava que 68,1 milhões de pessoas receberam alguma parcela do benefício. Para comparação, em setembro de 2020, o Brasil contava com 38.251.026 empregos formais, segundo o Caged. Ou seja, o Brasil tinha quase o dobro de pessoas em situação de extrema vulnerabilidade que em empregos formais, o que mostra a importância do programa e sua magnitude. Com tamanha vulnerabilidade prévia no mercado de trabalho, é preciso ter em mente que para uma parcela expressiva da sociedade 
brasileira que recebeu o auxílio emergencial, do qual trataremos mais à frente, a renda garantida pelo auxílio pode ter sido maior que a renda comumente obtida antes da pandemia.

Um olhar mais detalhado sobre os beneficiários do auxílio mostra que 19,5 milhões eram beneficiários do PBF, 10,5 milhões do CadÚnico e 38,1 milhões que se cadastraram pelo aplicativo/site. Foram injetados na economia pelo auxílio emergencial, até a data apontada, $\mathrm{R} \$$ 223,17 bilhões, sendo R \$ 75,93 bilhões para beneficiários do PBF, R \$ 33,57 bilhões para pessoas no CadÚnico e R $\$ 113,67$ bilhões para pessoas que se cadastraram pelo aplicativo/site. Os dados mostram, portanto, que o público do auxílio emergencial acabou sendo muito mais amplo que o do PBF, o que coloca uma questão sobre se antes da pandemia já teria sido necessário ampliar a assistência social e também se passada a fase aguda da crise será necessário também ampliar a assistência social.

Os indicadores discutidos neste artigo mostram que a crise pode impactar as trajetórias de muitas famílias brasileiras por muito tempo: ampliação da pobreza, do trabalho infantil, do desemprego, ainda que pontual, pode ser uma cicatriz. Para o caso do Brasil, não fosse a atuação do Legislativo em pressionar o Governo Federal para a criação de um auxílio emergencial nos moldes efetivamente adotados, os impactos sociais da pandemia poderiam ter sido muito mais devastadores. Em um país com profunda vulnerabilidade e informalidade e em um momento de interrupção brusca e brutal da atividade econômica, fez-se necessário um auxílio emergencial que recompusesse a renda de parte da população. Para além de reduzir as perdas das famílias, os estudos mostram que este benefício amorteceu o impacto econômico da perda de renda no consumo das famílias, tendo inclusive um sentido econômico anti-cíclico no momento de crise (FREIRE ET AL, 2020).

\section{Considerações finais}

O auxílio emergencial foi planejado para suprir uma demanda em um período relativamente curto de tempo. No entanto, os indicadores socioeconômicos não são animadores e há indicativos de que o mercado de trabalho siga em crise por um tempo. Assim, é necessário ampliar o auxílio emergencial para além de 2020.

Para além de pensar em prolongá-lo por mais alguns meses, é possível utilizar a experiência para criar algum modelo de renda básica permanente e refletir sobre o fato de nossos sistemas de proteção não serem inclusivos o suficiente: a "economia" feita ao sabotar sistemas protetivos mais amplos e por isso mais eficientes pode cobrar alto custo, em especial em momentos de crise. Em situações de emergência como a que vivemos agora, países que contam com uma rede de proteção social sólida estão mais preparados para responder com rapidez e eficiência (ILO, 2020). Por isso a OIT (ILO, 2020) tem insistido que a proteção social precisa ser vista como um investimento, não como um custo adicional, por ter papel vital como colchão e 
como estabilizador econômico essencial para o bom funcionamento da sociedade em especial em momentos de crise. É preciso usar esta oportunidade para ampliar os sistemas de proteção social como base de uma nova arquitetura econômica e social; para estudar a permanência para a posteridade de algumas medidas de proteção social adotadas durante a crise; e para usar a pandemia como um lembrete poderoso de que, em nosso mundo interconectado, a fraqueza do sistema de saúde e de proteção social de um país representa um risco para todos.

No entanto, passado o choque inicial com a gravíssima situação sanitária e socioeconômica enfrentada pelo país em 2020, há um diálogo no Congresso Nacional para mais uma alteração profunda no arcabouço institucional brasileiro: o auxílio emergencial (ou sua transformação em um novo programa de transferência de renda que substitua o PBF) tem sido utilizado como subterfúgio para ampliar a pressão sobre as chamadas "reformas estruturais" que reduzem o papel do Estado no desenvolvimento econômico e ampliam a adesão à austeridade fiscal (como o foram o novo regime fiscal com a Emenda Constitucional 95/2016, a reforma trabalhista de 2017 com a Lei 13.467/2017 e a reforma da previdência de 2019 com a Emenda Constitucional 103/2019), sendo a reforma da vez a Reforma Administrativa. Desta forma, está nas mãos do Congresso Nacional decidir se, ao invés de o auxílio emergencial (ou algum tipo de renda básica ou ampliação do PBF) ser integrado a uma provisão pública de direitos sociais, na prática ele será usado para reduzir ainda mais o papel do Estado em uma perspectiva de longo prazo. Novamente, o Congresso Nacional terá papel fundamental em definir se esta reforma, com a suposta justificativa de direcionar mais recursos aos pobres e miseráveis a partir da experiência do auxílio emergencial, será aprovada.

\section{Referências}

ABÍLIO, Ludmila. Uberização do trabalho: subsunção real da viração. Blog da Boitempo, 2017. Disponível em: https://bit.ly/3deKpWY. Acesso em: 20 jun. 2020.

AGÊNCIA CÂMARA DE NOTÍCIAS. Câmara aprova auxílio de R 600 para pessoas de baixa renda durante epidemia. 2020. Disponível em: https://bit.ly/38BgCac. Acesso em: 7 jul. 2020.

AGÊNCIA SENADO. Governo sanciona auxílio emergencial sem mudanças no valor ou nos critérios. 2020. Disponível em: https://bit.ly/2O6hbPP. Acesso em: 21 jun. 2020.

ALLOATTI, Magali, OLIVEIRA, Ana Luíza Matos de. Deepening and widening the gap: the impacts of Covid-19 pandemic on gender and racial inequalities in the labor market, domestic work and domestic violence in Brazil. 2020. [no prelo]

ARO, Marcelo. Presidente, isso não é verdade. Vamos contar a história real? Fui relator do projeto. Seu governo foi contra o meu relatório desde o primeiro momento. Vocês não admitiam um valor acima de $\mathrm{R} \$ 200,00$. @ marceloaro, 11 jun. de 2020. Tweet. Disponível em: https://bit.ly/3fpgyx7. Acesso em: 8 jul. 2020. 
BOLSONARO, Jair. Depois do Congresso apoiar R $\$ 500$ para o auxílio emergencial, estudos do @govbr, com responsabilidade fiscal e apoio da liderança do governo na Câmara, o @ MinEconomia alcançou os $\mathrm{R} \$ 600$ pagos em 3 parcelas. O maior programa de auxílio aos mais necessitados do mundo!. @jairbolsonaro, 11 jun. de 2020. Tweet. Disponível em: https://bit.ly/2VZDEm6. Acesso em: 8 jul. 2020.

BRASIL. Câmara Dos Deputados. Projeto de Lei no 9.236, de 29 de novembro de 2017. Altera o $§ 11$ e acrescenta os $\S \S 12,13,14$ e 15 ao art. 20 da Lei $n^{\circ} 8.742$, de 7 de dezembro de 1993 , para dispor sobre parâmetros adicionais para caracterização da situação de vulnerabilidade social, para fins de elegibilidade ao Benefício de Prestação Continuada, pela pessoa com deficiência ou idosa. Disponível em: https://bit.ly/3e4B1FX. Acesso em: 7 jul. 2020.

BRASIL. Lei $\mathbf{n}^{\mathbf{0}}$ 13.982, de 2 de abril de 2020. Altera a Lei $\mathrm{n}^{\circ}$ 8.742, de 7 de dezembro de 1993, para dispor sobre parâmetros adicionais... 2020a . Disponível em: https://bit.ly/3e8XbXF. Acesso em: 7 jul. 2020.

BRASIL. Medida Provisória $\mathbf{n}^{\mathbf{0}}$ 937, de 2 de abril de 2020. Abre crédito extraordinário, em favor do Ministério da Cidadania... 2020b. Disponível em: https://bit.ly/3gtEcZk. Acesso em: 7 jul. 2020.

BRASIL. Lei no 13.998, de 14 de maio de 2020. Promove mudanças no auxílio emergencial instituído pela Lei $\mathrm{n}^{\circ} 13.982$, de 2 de abril de 2020; e dá outras providências. 2020c. Disponível em: https://bit.ly/3iJI5v1. Acesso em: 8 jul. 2020.

BRASIL. Decreto $\mathbf{n}^{\circ}$ 10.412, de 30 de junho de 2020. Altera o Decreto $n^{\circ} 10.316$, de 7 de abril de 2020, para prorrogar o período de pagamento do auxílio emergencial de que trata a Lei $\mathrm{n}^{\circ}$ 13.982, de 2 de abril de 2020. 2020d. Disponível em: https://bit.ly/32Xxarp. Acesso em: 18 nov. 2020.

BRASIL. Medida Provisória no 1.000, de 2 de setembro de 2020. Institui o auxílio emergencial residual para enfrentamento da emergência de saúde pública de importância internacional decorrente do coronavírus (covid-19)... 2020e. Disponível em: https://bit.ly/2INfDva. Acesso em: 18 nov. 2020.

CAIXA ECONÔMICA FEDERAL. Auxílio emergencial: clique aqui para ver os últimos números. 2020. Disponível em: https://bit.ly/3iH0MiU. Acesso em: 7 jul. 2020.

CEPAL. Pandemia de COVID-19 levará à maior contração da atividade econômica na história da região: cairá -5,3\% em 2020 2020a. Disponível em: https://bit.ly/31SoPW6. Acesso em: 18 jun. 2020.

CEPAL. El desafío social en tiempos del COVID-19. 2020b. Disponível em: https://bit.ly/2UXQAZh. Acesso em: 20 jun. 2020.

CEPAL; OIT. Coyuntura Laboral en América Latina y el Caribe: El trabajo en tiempos de pandemia: desafíos frente a la enfermedad por coronavirus (COVID-19). 2020. Disponível em: https://bit.ly/3fJEfQh. Acesso em: 20 jun. 2020.

CONGRESSO é autor de 9 em cada 10 medidas anticovid. Isto é, 2020. Disponível em: https://bit.ly/38yhwEw. Acesso em: 7 jul. 2020.

DIEESE. Política de Valorização do Salário Mínimo: Depois de 20 anos, reajuste fica abaixo da inflação (INPC). 2017. Disponível em: https://goo.gl/PCJPgV. Acesso em: 19 dez. 2018. 
DOMINGUES, Edson; FREIRE, Débora; MAGALHÃES, Aline Souza. Efeitos econômicos negativos da crise do coronavírus tendem a afetar mais a renda dos mais pobres. 2020. Nota Técnica NEMEA. Disponível em: https://bit.ly/3dqpnoA. Acesso em: 20 jun. 2020.

FERNANDES, Anaïs. Mulheres concentram perda de empregos formais na pandemia. Valor Econômico, 9 nov. 2020. Disponível em: https://glo.bo/2IMVohb. Acesso em: 15 nov. 2020.

FMI. Country Information. 2020. Disponível em: https://bit.ly/31VAljO. Acesso em: 18 jun. 2020.

FORNAZIER, Armando; OLIVEIRA, Ana Luíza Matos de. O ideário neoliberal no Brasil na década de 1990 e suas implicações no trabalho e nos setores produtivos. Oikos, Rio de Janeiro, v. 12, n. 1, 2017. Disponível em: https://goo.gl/XwYZKj. Acesso em: 21 nov. 2018.

FREIRE, Débora, DOMINGUES, Edson, MAGALHÃES, Aline, SIMONATO, Thiago, MIYAJIMA, Diego. Renda Básica Emergencial: uma resposta suficiente para os impactos econômicos da pandemia da COVID-19 no Brasil?. 2020. Nota Técnica NEMEA. Disponível em: https://bit.ly/32WagRn. Acesso em: 18 nov. 2020.

FUNDAÇÃO ABRINQ. Cenário da Infância e Adolescência no Brasil 2017. 2017. Disponível em: https://goo.gl/FP2g5k. Acesso em: 24 jan. 2019.

G1. Auxílio Emergencial: moradores do DF dormem na fila para sacar benefício de R\$ 600 . 2020. Disponível em: https://glo.bo/2O1dOKb. Acesso em: 7 jul. 2020.

HECKSHER, Marcos. Que fração dos postos de trabalho perdidos na pandemia já foi recuperada? IPEA - Nota de Conjuntura, n.1 4, out./dez. 2020. Disponível em: https://bit.ly/38UzMKr. Acesso em: 18 nov. 2020.

IBGE. Síntese de Indicadores Sociais 2018. 2018. Disponível em: https://goo.gl/4umrc1. Acesso em: 24 jan. 2019.

IBGE. PNAD Contínua: taxa de desocupação é de $\mathbf{1 2 , 2 \%}$ e taxa de subutilização é de $\mathbf{2 4 , 4 \%}$ no trimestre encerrado em março de 2020. 2020. Disponível em: https://bit.ly/3fLeY8a. Acesso em: 20 jun. 2020.

ILO. Social protection responses to the COVID-19 crisis: Country responses and policy considerations. 2020. Disponível em: https://bit.ly/3fNmnEh. Acesso em: 20 jun. 2020.

ILO; UNICEF. ILO Monitor: COVID-19 and the world of work. Fourth edition Updated estimates and analysis. 2020. Disponível em: https://bit.ly/2NswCSp. Acesso em: 20 jun. 2020.

MELLO, Guilherme; OLIVEIRA, Ana Luíza Matos de; GUIDOLIN, Ana Paula; DE CASO, Camila; DAVID, Grazielle; NASCIMENTO, Julio Cesar; GONÇALVES, Ricardo; SEIXAS, Tiago. A Coronacrise: natureza, impactos e medidas de enfrentamento no Brasil e no mundo. 2020. Disponível em: https://bit.ly/2MpPiRX. Acesso em: 11 maio 2020.

NASSIF-PIRES, Luiza; CARVALHO, Laura; RAWET, Eduardo. Multidimensional Inequality and COVID-19 in Brazil. Public Policy Brief, n. 153, 2020.

OLIVEIRA, Ana Luíza Matos de. Desigualdade no início do século XXI: o Brasil na contramão mundial? Argumentum, v. 11, n. $3, \quad$ p. 171-186. https://doi.org/10.18315/argumentum.v11i3.24810. Acesso em: 11 maio 2020. 
OLIVEIRA, Ana Luíza Matos de, EMÍDIO, Ana Paula. The great equalizer?: The long-lasting effects of the Covid-19 pandemic on poverty and inequality in Latin America. 2020. [no prelo]

OLIVEIRA, Ana Luíza Matos de, PASSOS, Luana, GUIDOLIN, Ana Paula, WELLE, Arthur, NASSIF-PIRES, Luiza. Austeridade, pandemia e gênero. In: DWECK, Esther, ROSSI, Pedro, OLIVEIRA, Ana Luíza Matos de. Economia pós-pandemia: desmontando os mitos da austeridade fiscal e construindo um novo paradigma econômico no Brasil. São Paulo: Autonomia Literária, 2020.

OXFAM. País Estagnado: Um Retrato das Desigualdades Brasileiras 2018. 2018. Disponível em: https://goo.gl/SGVDUR. Acesso em: 24 jan. 2019.

PcdoB. Auxílio emergencial é medida em defesa da vida, diz Jandira. 2020. Disponível em: https://bit.ly/3pOmeq3. Acesso em: 18nov. 2020.

PIRES, Breiller. Jovens internados mostram 'rejuvenescimento' da covid-19 no Brasil. El País, 2020. Disponível em: https://bit.ly/3dkCckf. Acesso em: 20 jun. 2020.

PSOL. Emenda do PSOL quer impedir corte de novas parcelas do auxílio emergencial a 6 milhões de beneficiários. 2020. Disponível em: https://bit.ly/2IQzxVA. Acesso em: 18 nov. 2020.

PT. PT reage a corte de auxílio emergencial decretado por Bolsonaro e vai lutar para manter o valor em R\$ 600 2020. Disponível em: https://bit.ly/3pG0Pz8. Acesso em: 18 nov. 2020.

RESENDE, Thiago. Governo contraria promessa, e Bolsa Família não bate recorde. Folha de São Paulo, 2020. Disponível em: https://bit.ly/2O2tzQO. Acesso em: 7 jul. 2020.

SECOMVC. Atenção. @ secomvc, 9 de abr de 2020. Disponível em: https://bit.ly/2ZdQL1Q. Acesso em: 8 jul. 2020.

UOL. Guedes afirma que governo vai pagar $\mathbf{R} \$ 200$ para trabalhador informal. 2020. Disponível em: https://bit.ly/3dtz3yF. Acesso em: 21 jun. 2020. 